\title{
Article \\ Carbon Aerogel Based Waterborne Ultra-Black Coatings with High Light Absorption
}

\author{
Jie $\mathrm{Xu}^{1}$, Yifan $\mathrm{Shi}^{2}{ }^{2}$, Jiangling $\mathrm{Li}^{3}$, Guangzhen $\mathrm{Cui}^{3, *}$ and Guangxin $\mathrm{Gu}{ }^{1, *}$ \\ 1 Academy for Engineering and Technology, Fudan University, Shanghai 200433, China; xujie5336@163.com \\ 2 School of Chemistry and Materials Science, Liaoning Shihua University, Dandong Road 1, \\ Fushun 113001, China; Yifan_shi0404@163.com \\ 3 Key Laboratory of Science and Technology on Electromagnetic Environmental Effects and Electro-Optical \\ Engineering, The Army Engineering University of PLA, Nanjing 210007, China; lj1506@126.com \\ * Correspondence: cgzovezy@163.com (G.C.); guangxingu@fudan.edu.cn (G.G.)
}

Citation: Xu, J.; Shi, Y.; Li, J.; Cui, G.; $\mathrm{Gu}, \mathrm{G}$. Carbon Aerogel Based Waterborne Ultra-Black Coatings with High Light Absorption. Coatings 2021, 11, 563. https://doi.org/ 10.3390/coatings 11050563

Academic Editor: Ivan Jerman

Received: 17 April 2021

Accepted: 6 May 2021

Published: 11 May 2021

Publisher's Note: MDPI stays neutral with regard to jurisdictional claims in published maps and institutional affiliations.

Copyright: (c) 2021 by the authors. Licensee MDPI, Basel, Switzerland. This article is an open access article distributed under the terms and conditions of the Creative Commons Attribution (CC BY) license (https:// creativecommons.org/licenses/by/ $4.0 /)$.

\begin{abstract}
In this paper, we wish to report the preparation of ultra-black films via spraying coatings composed of waterborne binders and low-cost carbon aerogels on pre-treated tinplate. The CAs were prepared by annealing resorcinol-formaldehyde resin ( $\mathrm{RF}$ resin) and the following $\mathrm{CO}_{2}$ activation, of which the reflectance was less than $0.4 \%$ in a wide wavelength range. The reflectance of different coatings, which using CAs as functional pigments, ranged from $1.8 \%$ to $4.3 \%$ in the visible light region $(400-760 \mathrm{~nm})$, while it ranged from $1.9 \%$ to $4.2 \%$ in the near-infrared region $(760-1100 \mathrm{~nm})$. Further studies revealed the relationship between the pigment-to-binder ratio and reflectance and found the best ratio to be 0.96 , and the minimum reflection was less than $1.8 \%$. Outstanding adhesion to the tinplate substrate was also achieved using a two-component polyurethane binder after the thermal cycling test carried out from $-100{ }^{\circ} \mathrm{C}$ to $100{ }^{\circ} \mathrm{C}$. The fabrication process of ultra-black coatings is particularly convenient to remove the constraints of high costs and complex processes, making it instructive guidance for industrial production.
\end{abstract}

Keywords: carbon aerogels; high light absorption; ultra-black coating; waterborne binder; outstanding adhesion

\section{Introduction}

Since the 'black body' theory was first introduced into thermodynamics by Kirchhoff and the law of black body radiation was proposed by Planck [1,2], the interest in the research of ideal electromagnetic absorbers [3] to simulate a black body gradually arose [4]. Great efforts have been made toward the design, synthesis, and optimization of such materials because of the outstanding optical and thermal properties introduced by their high light absorptivity [5,6]. Therefore, various materials based on metal, carbon, silicon, etc., were reported to possess excellent light absorbing property [7-12] and applied to different fields, such as photothermal conversion [13,14], optical instrumentation [15,16], aerospace applications, as well as satellites [17-19]. As far as we know, the properties of high light absorbing of ultra-black materials originate from the periodic structures endowed by nature or by artificial designing [7,20-23], such as needle-like 'forest' or inverse V-type structures. Steglich et al. managed to fabricate an ultra-black silicon absorber with needlelike forest morphology to process an absorptance of more than $99.5 \%$ [11]. Through bionics, Zhao et al. pyrolyzed the scale wings of Ornithoptera goliath butterfly at $650{ }^{\circ} \mathrm{C}$ and finally obtained the ultrathin inverse V-type structure anti-reflection materials entirely consisting of carbon and having a reflectance of $<1 \%$ in the visible light region [24]. In recent years, carbon materials, for instance, carbon nanotubes (CNTs) [25-27], carbon aerogels (CAs) [28,29], carbon foam [30], carbon fiber composites [31], and carbon spheres (CSs) [32], as research hotspots, were reported to possess not only good capacitive performance [33,34] but also great light absorptivity in both visible and infrared regions, which was attributed 
to the peculiar porous structures, large conjugated system and moderate free-electron density of carbon [35]. Moreover, low density and a wide source of raw materials are excellent advantages of these materials in industrial applications compared with other element-based materials [36]. Therefore, multiple carbon materials have been applied to produce ultra-black coatings with extremely low reflectance. Magdassi et al. reported carbon nanotube black coating using multi-walled carbon nanotubes (MWCNTs) mixed with a silicon-based binder to obtain a reflectance of $<4 \%$ in the visible light region and $<5 \%$ in the near-infrared region [26]. Theoretically, a subwavelength structure was demonstrated by Sun et al., in which light absorption resulted from the reduced electron mean free path in subwavelength micropores [37]. This conclusion helped us in designing coatings with subwavelength structures in order to reduce diffuse light reflection. Additionally, by adjusting the ratio of the reactants and catalyst in precursor solutions, various preparation processes have been developed and improved for fabricating artificial CAs with three dimensional porous subwavelength structures since first synthesized by Pekala [38-41]. Therefore, we tried to apply the subwavelength structured CAs as functional fillers to prepare coatings with high light absorption.

In this study, an appropriate ratio of resorcinol, formaldehyde, and sodium carbonate in the precursor was determined to fabricate hydrosol. The resorcinol-formaldehyde solution was dissolved in deionized water (DIW) with sodium carbonate as base catalyst. Then, a hydrothermal process was performed to obtain the hydrogel. The final CAs with hierarchical porous nanostructures were derived from the pyrolysis of such hydrogel and a subsequent $\mathrm{CO}_{2}$ activation process. Coatings of different binder types composed of these carbon aerogels show a reflection of $<2.1 \%$ in the visible region and $<2.2 \%$ in the NIR region at the best experimental conditions. The mechanical properties of adhesion and thermal cycling tests prove that the coating is reliable enough for applications in extreme situations. Furthermore, the convenience of preparation and commercial availability of raw materials enable the facile realization of industrial production of such ultra-black coatings.

\section{Experimental}

\subsection{Materials}

Sodium carbonate, formaldehyde (37\% in water), resorcinol, and all other reagents were purchased from Sinopharm Chemical Reagent Co., Ltd. (SCR, Shanghai, China) and used as received without further purification. Anionic polyacrylate dispersion along with aliphatic isocyanate (2K-WPU), anionic polycarbonate modified polyurethane dispersion (DLC-F), and aliphatic anionic acid modified polyurethane dispersion (PUD) were purchased from Covestro Polymers (Shanghai, China) Co., Ltd. The two-component ceramic coating Sunactive CD200 (2K-CERA.) was purchased from Shanghai Kinlita Chemical Co., Ltd. (Shanghai, China) Other additives, wetting agents, flatting agents including dispersing agents were purchased from BYK-Chemie GmbH (Tongling, Germany). Both resin and additives were used as received.

\subsection{Synthesis of CAs Through the Sol-Gel Process}

The carbon aerogels were obtained via the carbonization of resorcinol-formaldehyde (RF) gels, which derived from the addition reaction and polycondensation reaction under alkaline condition provided by sodium carbonate. The molar ratio of formaldehyde to resorcinol (F/R) was adjusted to 2, and this mixture was dissolved in a certain amount of deionized water. Subsequently, as a base catalyst, alkaline sodium carbonate (C) was added, with the molar ratio of formaldehyde to the catalyst (F/C) being fixed at 600 . This aqueous solution was denoted as the precursor solution, the total weight of resorcinol and formaldehyde (W\%) was set at around 5\%. Typically, $3 \mathrm{~g}$ of resorcinol was added in a round bottom beaker containing $135 \mathrm{~mL}$ deionized water (DIW). Then, $4.2 \mathrm{~g}$ of formaldehyde was added dropwise under stirring. The resulting solution was stirred for $15 \mathrm{~min}$ and subsequently $9.6 \mathrm{mg}$ of sodium carbonate was added. After stirring for another $20 \mathrm{~min}$, the precursor solution was transferred into a polytetrafluoroethylene (PTFE) mold and 
sealed in a steel hydrothermal reactor. The reactor was cured in a constant temperature humidity chamber at $85^{\circ} \mathrm{C}$ for $72 \mathrm{~h}$. The resulting gel was soaked in acetone for $24 \mathrm{~h}$ for a few times to completely remove residual solvents and water. After the solvent exchange process, the wet gel was subsequently transferred into a fridge at $-16{ }^{\circ} \mathrm{C}$, stored for $3 \mathrm{~h}$ to keep the structure robust, and then dried in a freeze-dryer for $24 \mathrm{~h}$. The dried sol was carbonized at $900{ }^{\circ} \mathrm{C}$ under a nitrogen atmosphere for $2 \mathrm{~h}$. The resulting black cylindrical materials were the target product of CAs and named CA-S.

\subsection{Activation of $\mathrm{CAs}$ with $\mathrm{CO}_{2}$}

CA-S were annealed in a tubular furnace at $1000^{\circ} \mathrm{C}$ for $2 \mathrm{~h}$ under the mixture gas environment $\left(\mathrm{N}_{2}\right.$ flow of $75 \mathrm{~mL} \cdot \mathrm{min}^{-1}$ and $\mathrm{CO}_{2}$ flow of $\left.75 \mathrm{~mL} \cdot \mathrm{min}^{-1}\right)$. The heating rate was set at $10^{\circ} \mathrm{C}$ per minute from room temperature to the target temperature, and the natural cooling process was followed. Both the heating and cooling processes were performed under a nitrogen atmosphere at a flow rate of $250 \mathrm{~mL} \cdot \mathrm{min}^{-1}$. The obtained CAs activated by $\mathrm{CO}_{2}$ were denoted as ACA.

\subsection{Preparation of Ultra-Black Coating}

In the primary formulation, the $\mathrm{CA}$ aqueous dispersion was mixed with various ratios of different binders to fabricate different polymer-based ultra-black coatings. For a typical experiment, a certain amount of dispersing agent $(10 \mathrm{~g})$ was added to $70 \mathrm{~mL}$ deionized water, which was stirred using a laboratory mill for $10 \mathrm{~min}$ in a plastic beaker at ambient temperature. With a stirring speed of $400 \mathrm{rpm}, 20 \mathrm{~g}$ ACA was added gradually to avoid splashing due to the low pile density. On completely adding ACA, the stirring speed was increased to $2000 \mathrm{rpm}$ and maintained for $1 \mathrm{~h}$ to acquire the ACA aqueous dispersion. A certain amount of resin (2K-WPU/PUD/2K-CERA./DLC-F) was added in another plastic beaker, followed by the dropwise addition of additives with a stirring speed of $700 \mathrm{rpm}$. Then, the ACA aqueous dispersion was added, and the resulting solution was dispersed using a laboratory mill at a speed of $700 \mathrm{rpm}$ for $60 \mathrm{~min}$ to obtain the ultra-black coatings.

\subsection{Characterization}

The microscopic structures of the carbon aerogels were investigated using scanning electron microscopy SEM (JSM-7800F, Japan Electronics Corporation, Tokyo, Japan). The crystal structure of the sample was examined on an X-ray diffraction instrument (XRD, Bruker D8 Advance, Leipzig, Germany), with Cu target $(0.154 \mathrm{~nm})$ as the radiation source, tube voltage of $40 \mathrm{kV}$, tube current of $40 \mathrm{~mA}$, and scanning speed of $5^{\circ} \mathrm{min}^{-1}$. Absorbance was identified indirectly by measuring the reflectance of the film at wavelengths ranging from $1100 \mathrm{~nm}$ to $400 \mathrm{~nm}$ using a U-4100 Spectrophotometer (HITACHI). Thermogravimetric analysis (TGA) was performed on TA Q500 (TA Instruments, New Castle, CA, USA) under a nitrogen atmosphere. Raman spectra (ThermoFisher Scientific DXR2xi, Waltham, MA, USA) were recorded from $600 \mathrm{~cm}^{-1}$ to $2500 \mathrm{~cm}^{-1}$ under $532 \mathrm{~nm}$ excitation. The pore size distribution and specific surface area were measured via the $\mathrm{N}_{2}$ adsorption method at $0{ }^{\circ} \mathrm{C}$ in a magnetic suspension balance using the Brunauer-Emmett-Teller (BET) nitrogen adsorption/desorption technique (ASAP 2020 V4,0 from Micromeritics, Norcross, GE, USA). Film thickness was measured using a SURFIX B thickness gauge from PHYNIX $\mathrm{GmbH} \& \mathrm{Co}$. KG, Neuss, Germany. The adhesion properties were measured through an ISO2409/ASTM D3359 [42,43] cross-cut test and evaluated using the above standards.

\section{Results}

The synthesis of the RF aerogels is schematically illustrated in Figure 1. Commercially available raw materials of resorcinol and formaldehyde can easily co-dissolve in deionized water and form a semi-opaque hydrosol using sodium carbonate as the base catalyst under alkaline conditions. The obtained precursor solution was sealed in a PTFE mold and subjected to a low-temperature hydrothermal process at $85^{\circ} \mathrm{C}$ for $72 \mathrm{~h}$. The resulting hydrogel was soaked in acetone for $24 \mathrm{~h}$, the process was replicated 3 times to remove 
the residual water and solvent. After the freeze-drying process, the cylindrical product was pyrolyzed at $900{ }^{\circ} \mathrm{C}$ in a tubular furnace for $2 \mathrm{~h}$. In this process, to protect the morphological structure of CAs from collapsing, a heating rate of $10^{\circ} \mathrm{C} / \mathrm{min}$ from ambient temperature to $400{ }^{\circ} \mathrm{C}$ and $5{ }^{\circ} \mathrm{C} / \mathrm{min}$ from $400{ }^{\circ} \mathrm{C}$ to $900{ }^{\circ} \mathrm{C}$ was engaged under a nitrogen environment. During the activation procedure, we controlled the flow rate of carbon dioxide and nitrogen to maintain an appropriate etching efficiency in order to stabilize the original three-dimensional structure.

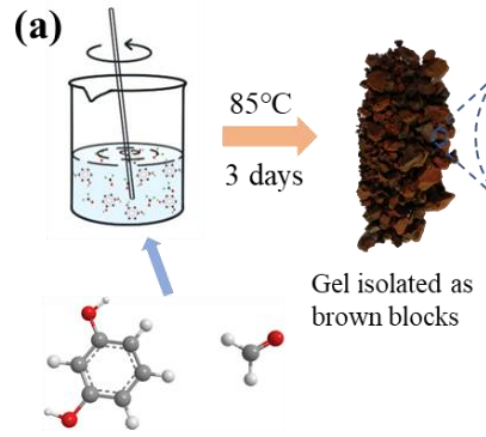

Resorcinol Formaldehyde
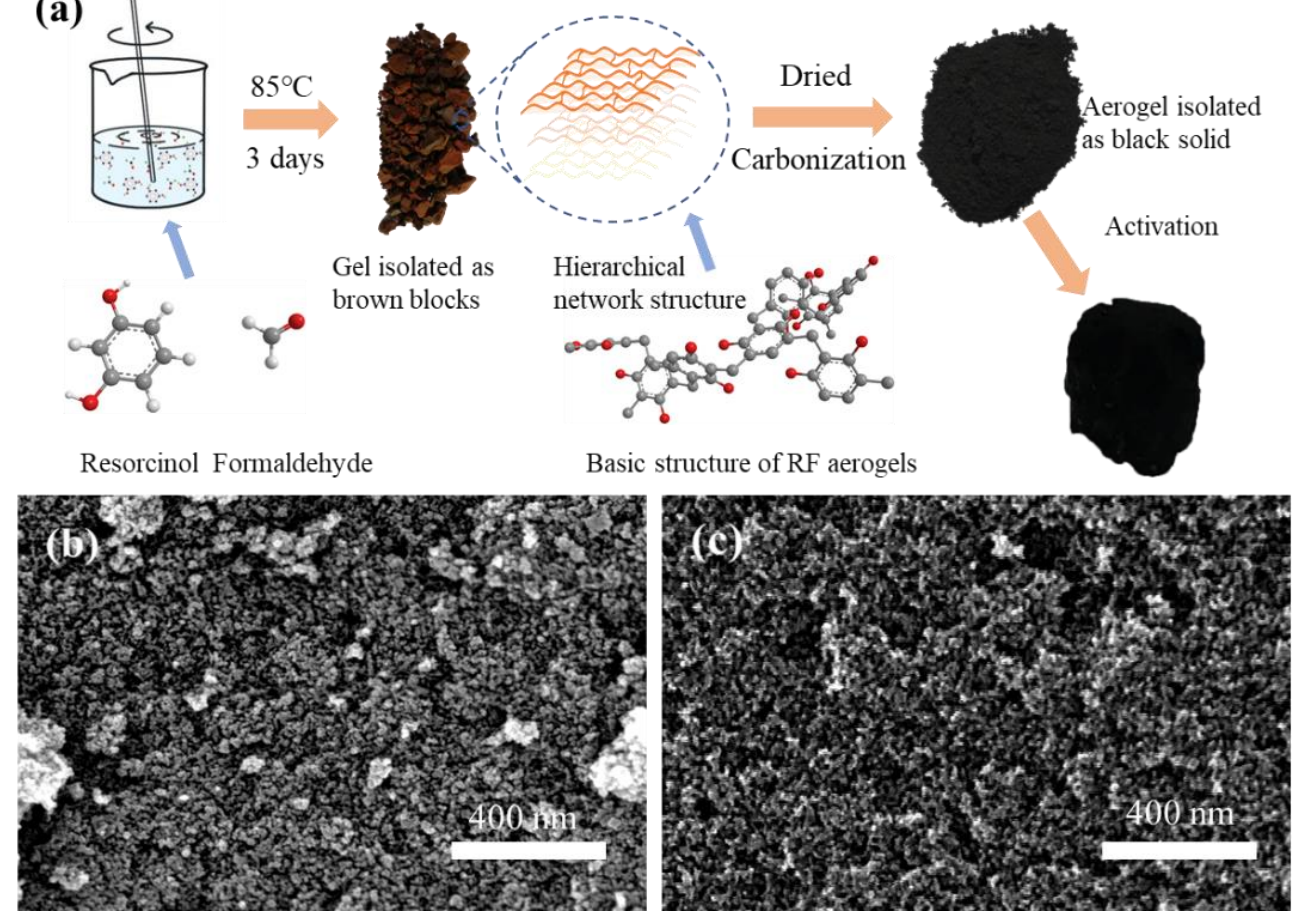

Figure 1. Fabrication and morphology of carbon aerogels. (a) Schematic illustration of the fabrication process. Resorcinol and formaldehyde hydrosol were converted into hydrogel by hydrothermal process, freeze-dried for $24 \mathrm{~h}$, and annealed at $900{ }^{\circ} \mathrm{C}$ to form the porous carbon aerogels, and the activating process built more nanostructure pores resulting in a lower reflectance. SEM images of (b) CA-S and (c) ACA. The scale bar is $400 \mathrm{~nm}$.

Subsequently, the process to prepare CAs with subwavelength structures was performed, as illustrated in Figure 1. According to its morphology, more pores and microstructures exist in ACA than in CA-S on comparing the SEM images (Figure 1b,c). For the purpose of analyzing the type of carbon in these two samples (CA-S and ACA), Raman spectra were recorded and shown in Figure 2a. The spectrum of both samples shows two characteristic peaks located at approximately $1355 \mathrm{~cm}^{-1}$ and $1585 \mathrm{~cm}^{-1}$, which are ascribed to the $\mathrm{D}$ band and $\mathrm{G}$ band, respectively. The $\mathrm{D}$ band results from disordered carbon and other defects, whereas the $\mathrm{G}$ band is assigned to the zone center $E_{2 g}$ mode, which is the consequence of the ordered $\mathrm{sp}^{2}$ bonded carbon [44]. Moreover, $\mathrm{X}$-ray diffraction analysis was performed, and the results are shown in Figure $2 b$. The XRD pattern of both CA-S and ACA exhibits two diffraction peaks at $2 \theta$ of around $24^{\circ}$ and $44^{\circ}$, corresponding to the $\left(\begin{array}{ll}0 & 0\end{array}\right)$ and (1 01 1) planes, respectively. These data imply that carbon aerogels are composed of both graphite carbon and amorphous carbon $[45,46]$. Nevertheless, the activation step shows a limited effect on the major structure and the type of carbon due to the similar curves. To further study the difference in physical properties after activation, more measurements were performed. 

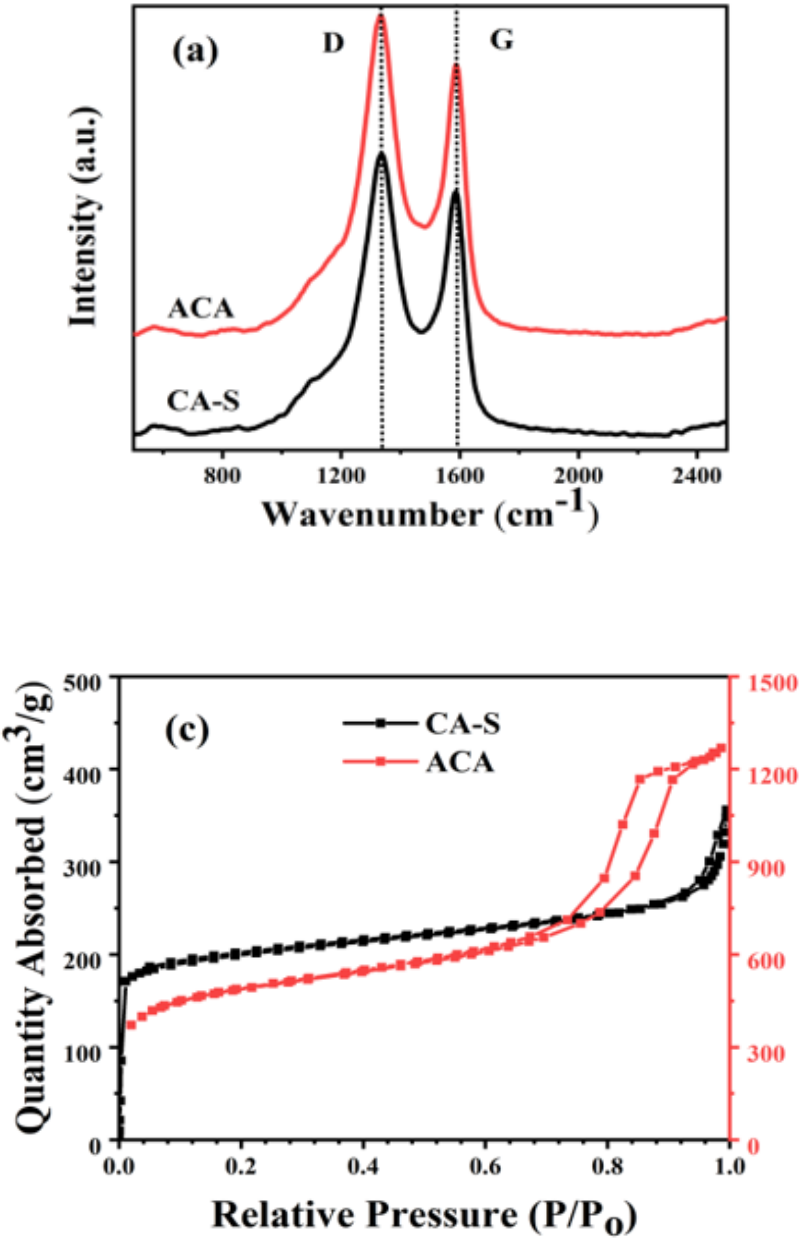
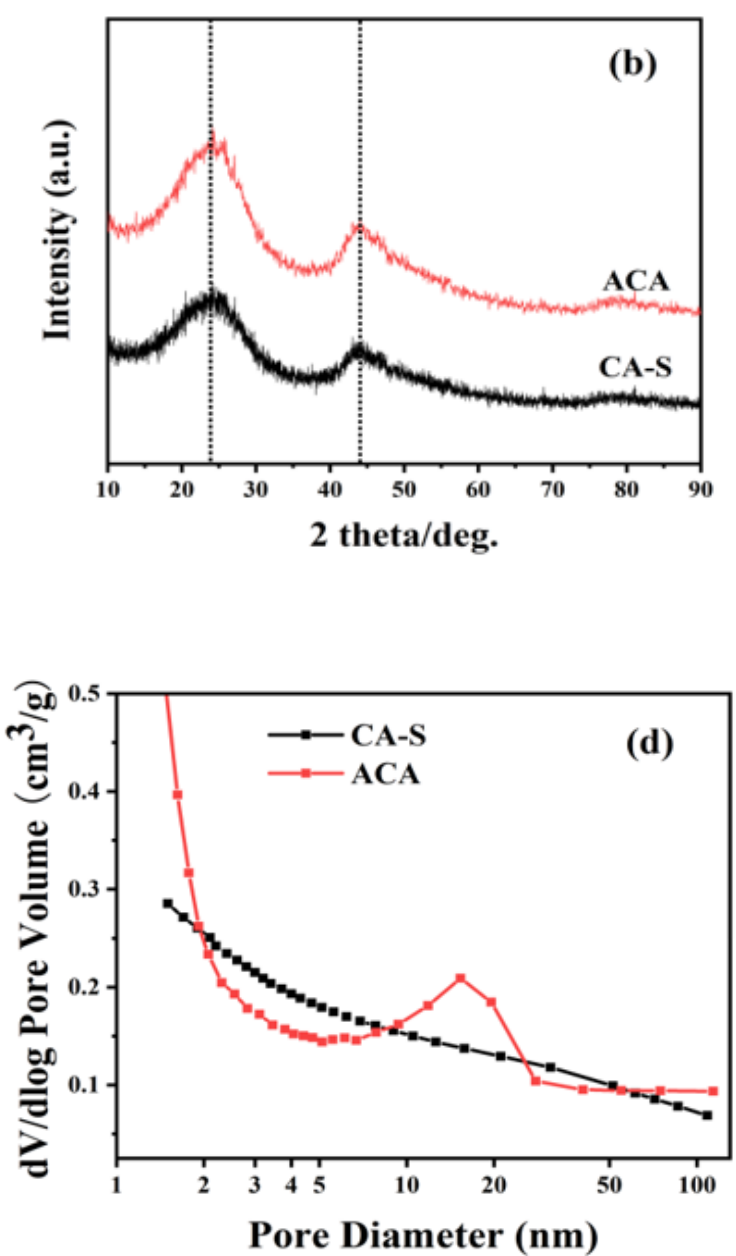

Figure 2. (a) Raman spectra of ACA and CA-S. (b) X-ray diffraction patterns of ACA and CA-S. (c) Isotherms of ACA and CA-S. (d) BJH pore distribution of ACA and CA-S.

The pore structures of CA-S and ACA were investigated via low-temperature $\mathrm{N}_{2}$ absorption-desorption measurements. Brunauer-Emmett-Teller specific surface areas as high as $1544.7 \mathrm{~m}^{2} / \mathrm{g}$ and $649.7 \mathrm{~m}^{2} / \mathrm{g}$ were measured for ACA and CA-S, respectively. Using the $t$-plot method, the micropore surface area and mesopore/macropore surface area of CA-S and ACA were calculated to be $448.22 \mathrm{~m}^{2} / \mathrm{g}$ and $201.42 \mathrm{~m}^{2} / \mathrm{g}$ and $911.52 \mathrm{~m}^{2} / \mathrm{g}$ and $633.13 \mathrm{~m}^{2} / \mathrm{g}$, respectively. The activated process produced twice the micropores and thrice the mesopores, which was in good accordance with the isotherms shown in Figure 2c. The isotherm curve of ACA can be classified as type IV, while that of CA-S can be classified as type II, according to the IUPAC classification of adsorption isotherms [47]. The black line in Figure 2c for CA-S rapidly elevates at a low relative pressure $\left(\mathrm{P} / \mathrm{P}_{0}\right)$, indicating the formation of abundant micropores. The absorption continues to increase without a plateau near $\mathrm{P} / \mathrm{P}_{0}$ of 1.0 , suggesting the presence of mesopores and relative macropores. In contrast, the hysteresis loop of the red line for ACA in Figure 2c is associated with capillary condensation taking place in its mesopores, and the initial part of the isotherm is attributed to monolayermultilayer adsorption [48]. Furthermore, the BJH absorption pore-size distribution was determined, which showed the expected results (Figure 2d). The corresponding poresize distribution of both the samples before and after activation samples shows a highintensity peak at the abscissa of $1-5 \mathrm{~nm}$, especially $1-2 \mathrm{~nm}$, and the slope of ACA is more precipitous than that of CA-S during the micropore range, indicating that the samples, particularly ACA, had abundant micropores with diameters of 1-2 $\mathrm{nm}$ on the nanostructure framework. Notably, the average pore size decreased significantly in the range of 10 to 
$100 \mathrm{~nm}$, demonstrating the transformation from micropores to mesopores, which is in accordance with the isotherm curve results and changes in BET specific surface area.

The absorption rate was measured indirectly by testing the reflectance of the materials, and the reflectance of CA-S and ACA is shown in Figure 3. The average reflectance of CA-S ranged from $0.78 \%$ to $0.60 \%$, while that of ACA was less than $0.40 \%$, indicating that the activation process has a positive effect in decreasing the reflectance due to the presence of more micropores and mesopores. The line chart shown almost a relatively flat slope ranging from $1100 \mathrm{~nm}$ to $400 \mathrm{~nm}$, which indicates uniform absorption in both visible and NIR regions. This feature helps in forming a uniform film, providing steady light absorbance in desired applications.

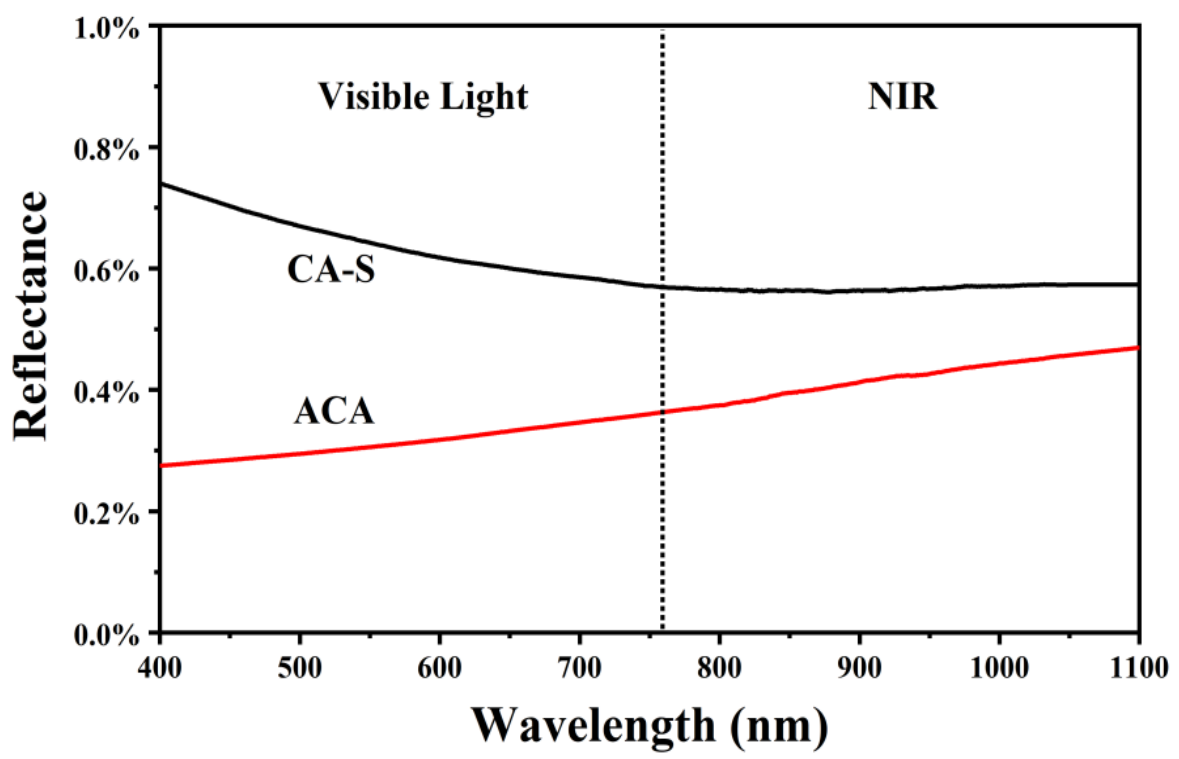

Figure 3. Reflection of CA-S and ACA.

Herein, we used ACA as the light-absorbing materials of the ultra-black coatings. In our primary formulation of coatings, four different types of binders were mixed well along with ACA aqueous dispersions, and the black coatings were formed by airbrush spraying such mixture onto pretreated Aluminum plate. For a typical preparation, $12 \mathrm{~g}$ of ACA aqueous dispersion was added into one-component, two-component, polycarbonatemodified waterborne polyurethane and silicon-based binder, and the pigment-to-binder ( $\mathrm{PB}$, the weight of pigment to the weight of resin in the dried film) ratio was set as 0.58 . The reflectance of the four types of coatings acquired by spraying was measured at the visible-NIR light region (400-1100 nm) and presented in terms of wavelength-to-reflectance. As shown in Figure 4a, the primary formulations of coatings exhibit some differences in the range of $400 \mathrm{~nm}$ to $1100 \mathrm{~nm}$. Moreover, the reflectance of the 2K-ceramic coating is about $1.8 \%$, while that of DLC-F is $4.3 \%$, which represented the best and the worst result, respectively. Furthermore, the average reflectance of $2 \mathrm{~K}-\mathrm{WPU}$ and PUD is $2.3 \%$ and $3.6 \%$, respectively. We assumed that the overall reflected light of the coating is composed of interfacial reflection due to the refractive index mismatch and backward scattering inside the coating film. To figure out whether the interfacial reflection plays an important role in the overall reflectance of different coatings, a pure resin film without any additive or pigment was brushed on a PET membrane with a coating rod (from RD Specialties, $100 \mu \mathrm{m})$, baked, and subjected to optical tests. Fortuitously, the results reveal almost the same reflectance curve (Figure $4 \mathrm{~b}$ ), and the deviation between the curves was less than $4 \%$; therefore, we can assume that the pure resins are basically similar. Interestingly, the DLC-F shows a lower reflectivity in the form of pure resin but the highest value was obtained on applying the ultra-black coating, suggesting that the reflectance of the clear coating itself has an extremely minor effect on the overall reflectance in the ultra-black coating. Moreover, 
SEM was performed to investigate the surface morphology of these four types of coatings in order to find out the reason for the difference in optical properties (Figure 5). Interestingly, the surface morphology of both $2 \mathrm{~K}$-ceramic coating and $2 \mathrm{~K}$-WPU seems more complicated than that of the other two samples (PUD and DLC-F) that presented lower reflectance. The differences may be due to the morphology change resulting from the polymerization of the two-component system, which is further enhanced with the presence of pigments. Accordingly, we can infer that a more complex surface morphology rather than a flat surface helps in decreasing the interfacial reflection of the dried film.
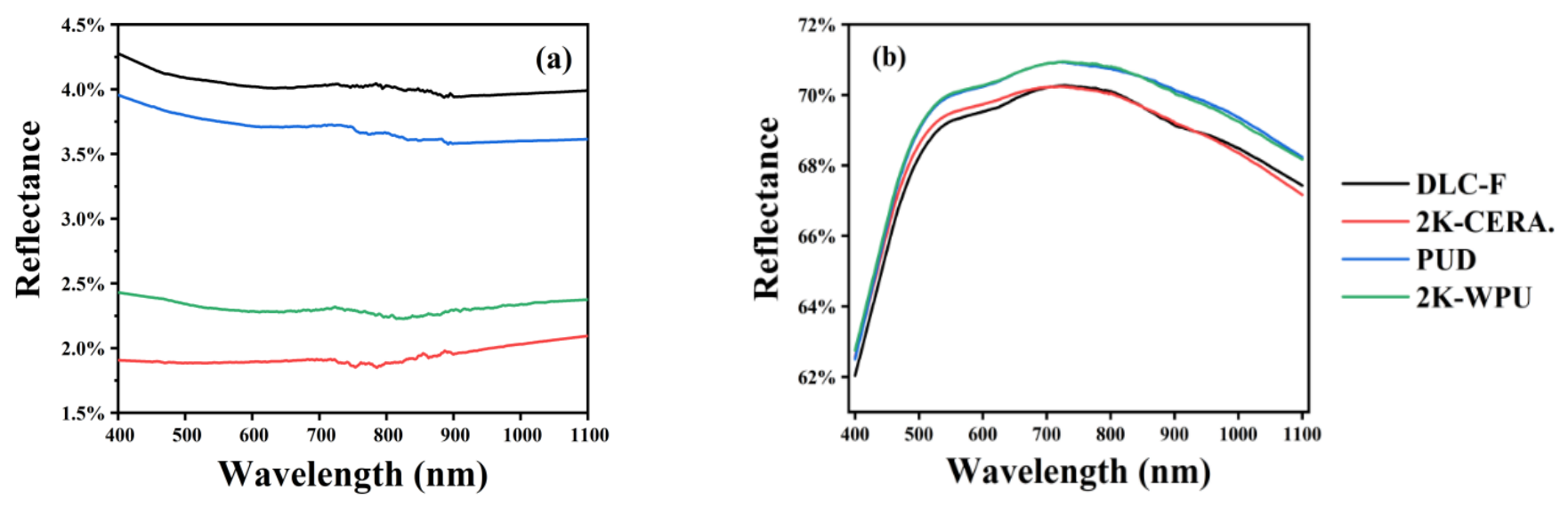

Figure 4. (a) Reflectance of primary coating formulations. (b) Reflectance of pure resin.
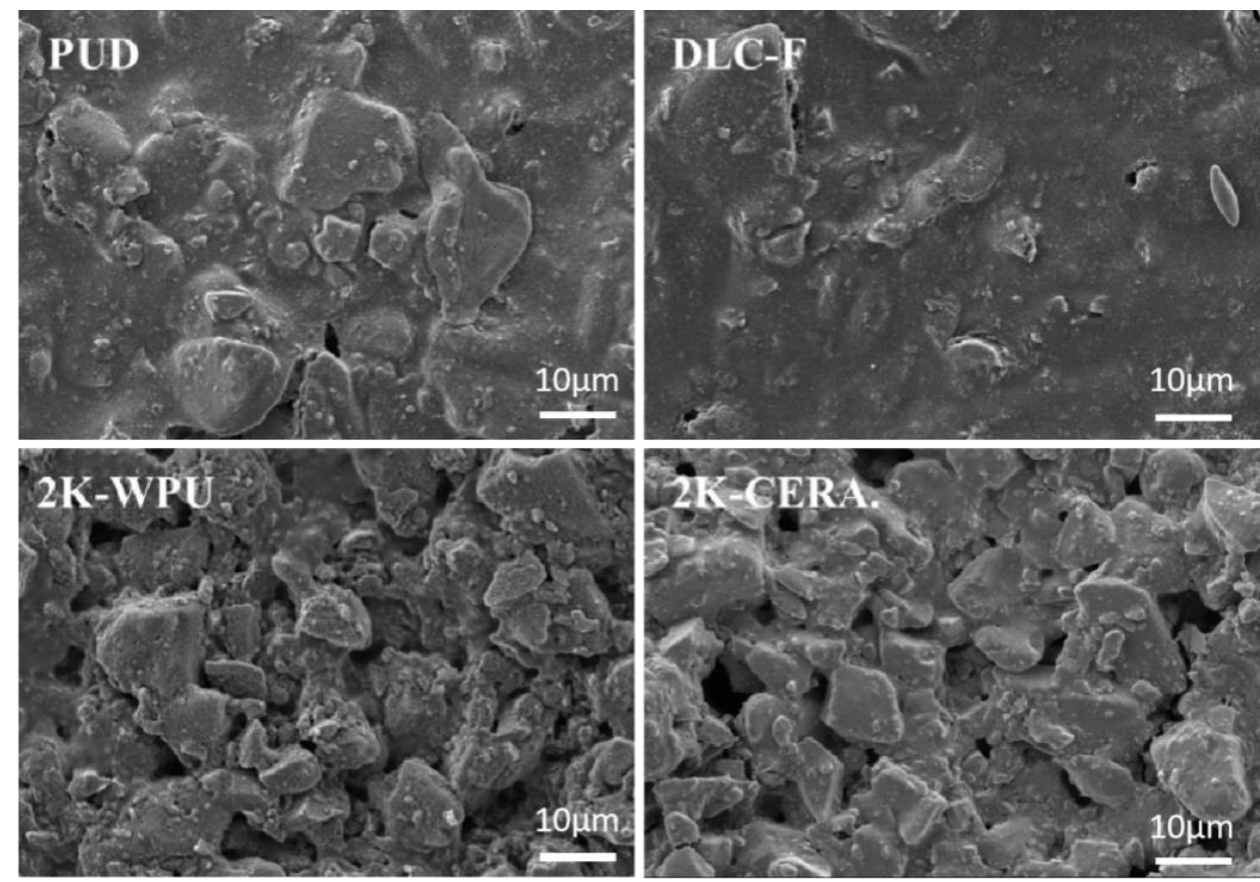

Figure 5. SEM of PUD, DLC-F, 2K-WPU, and 2K-CERA. film. The scale bar represents $10 \mu \mathrm{m}$.

Considering the practical applications of the material in aerospace optical auxiliary equipment, maintaining a steady weight is particularly important because weight is directly proportional to the orbital coefficients, so any change in weight under the weightlessness condition will result in changes in the orbit. Thus, TGA of the dry film was performed to determine the binder with the best thermal stability. To simulate the application situation, the coating film was heated to and maintained at $125^{\circ} \mathrm{C}$ and $150{ }^{\circ} \mathrm{C}$ for $30 \mathrm{~min}$ each, and a heating rate of $10^{\circ} \mathrm{C}$ per minute from $50{ }^{\circ} \mathrm{C}$ to $150{ }^{\circ} \mathrm{C}$ was used during the heating process. As shown in Figure 6, the 2K-WPU binder hardly lost any weight, with the weight loss 
ratio being less than $0.5 \%$, and was hence inferred to be the best. In contrast, the $2 \mathrm{~K}$-ceramic coating showed a $1 \%$ weight loss ratio, while both PUD and DLC-F have ratios significantly larger than 1\%. The slight increase in weight during the heating-up period is due to the adsorption of $\mathrm{N}_{2}$ at the surface of the porous CAs. Clearly, the thermal stability of two two-component coatings behaved better than the single component ones, indicating the better intermolecular combination of the two-component system, which can lead to better physical and chemical properties.

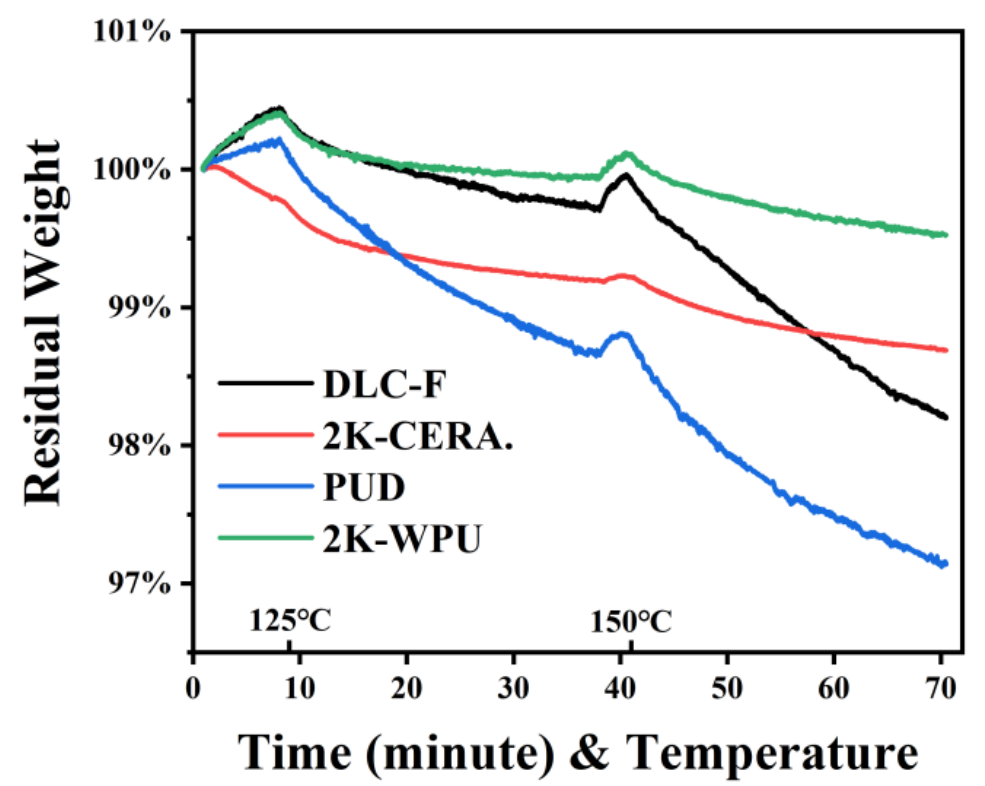

Figure 6. TGA analysis of PUD/DLC-F/2K-WPU/2K-CERA. film.

The adhesion property of the coatings to the substrates was evaluated using the ISO 2409/ASTM D3359 tape test with cross-cuts. The adhesion property is marked by the fraction of detachment of the coating. Typically, the film thickness should be less than $60 \mu \mathrm{m}$, and the cross-cutting spacing was set to $1 \mathrm{~mm}$, using adhesive tape to stick the cutting parts several times after cross-cutting. The results were evaluated via nakedeye observations and classified according to a standard scale (class 0 is the best with no detachment, class 5 is the worst with more than $65 \%$ detachment for ISO 2409 , class $5 \mathrm{~B}$ is the best with no detachment, class $0 \mathrm{~B}$ is the worst with more than $65 \%$ detachment for ASTM D3359). The typical adhesion results are presented in Figure 7.
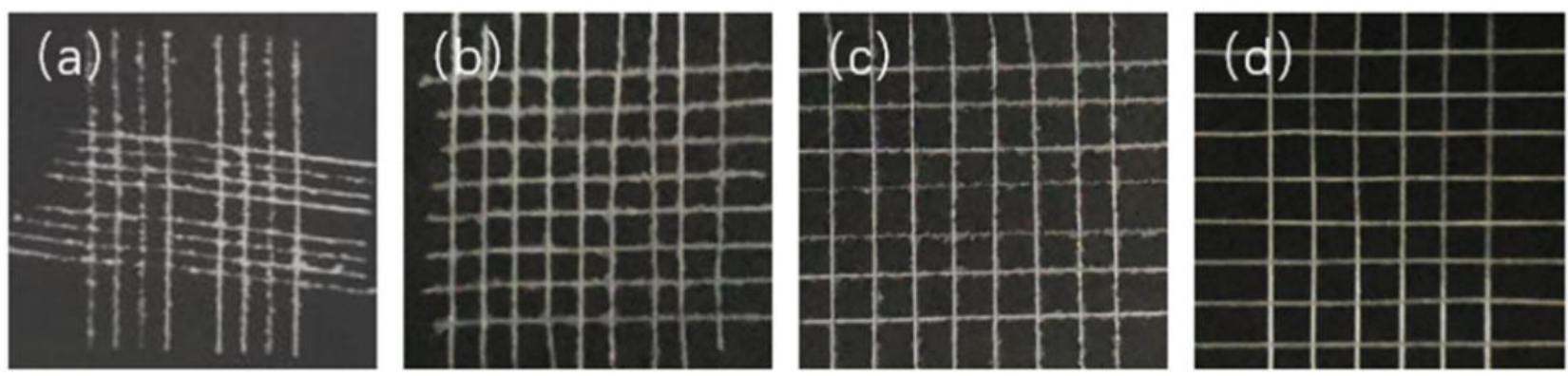

Figure 7. Typical adhesion images of (a) DLC-F, (b) 2K-CERA., (c) PUD, (d) 2W-WPU.

The $2 \mathrm{~K}-\mathrm{WPU}$ coating shows the best adhesion as ISO class 0/ASTM class 5B, while both the $2 \mathrm{~K}$-ceramic coating and PUD present ISO class 1 / ASTM class $4 \mathrm{~B}$ adhesion. In contrast, DLC-F shows the worst grade with ISO class 3/ASTM class 3B adhesion. We expected that the $2 \mathrm{~K}$-ceramic coating would exhibit good adhesion due to its good optical performance, but the result seems contrary. The low adhesion level would cause the loose 
combination of the coating and substrate, which resulted in a tiny interspace between the film and substrates. This interspace provided room for air bubbles, steam, or a trace amount of water, and the impurities will slowly increase and finally break through the coating film, forming micro-tunnels to let more impurities in, which will further enlarge the size of the tunnels. Considering the combined influence of poor adhesion in anti-corrosion, mechanical properties and weather resistance, we decided to use the 2K-WPU resin as the final binder for ultra-black coating.

The samples of different $\mathrm{PB}$ ratios ranging from 0.58 to 1.15 were brushed using a wire rod of $60 \mu \mathrm{m}$ onto polished aluminum plate and dried at room temperature for $20 \mathrm{~min}$ before being placed in an oven at $50{ }^{\circ} \mathrm{C}$ for another $2 \mathrm{~h}$, to finally obtain the dried film with a thickness of about $34 \mu \mathrm{m}$. As we expected, the sample of the lowest PB ratio (PB 0.58) shows the highest reflectance of $2.5 \%$, which decreases as the PB ratio increases (Figure 8 ). However, when the $\mathrm{PB}$ ratio reaches 0.96 , the reflectance reaches the lowest value (red line in Figure 8.). On increasing the PB ratio (1.06 and 1.15), negative results were acquired, i.e., the reflectance starts to increase. Although samples with a high PB ratio (less than 1) show better absorption properties, the adhesion property decreases as the $\mathrm{PB}$ ratio increases (Table 1). The samples with a PB ratio of 0.96 and below exhibit ISO class $0 /$ ASTM class 5B adhesion, while those over 0.96 show ISO class 1 / ASTM class $4 \mathrm{~B}$ adhesion. In summary, the larger the PB ratio, the worse would be the adhesion. Therefore, in this study, a PB ratio of 0.96 was selected as the optimal choice for both good reflectance and adhesion.

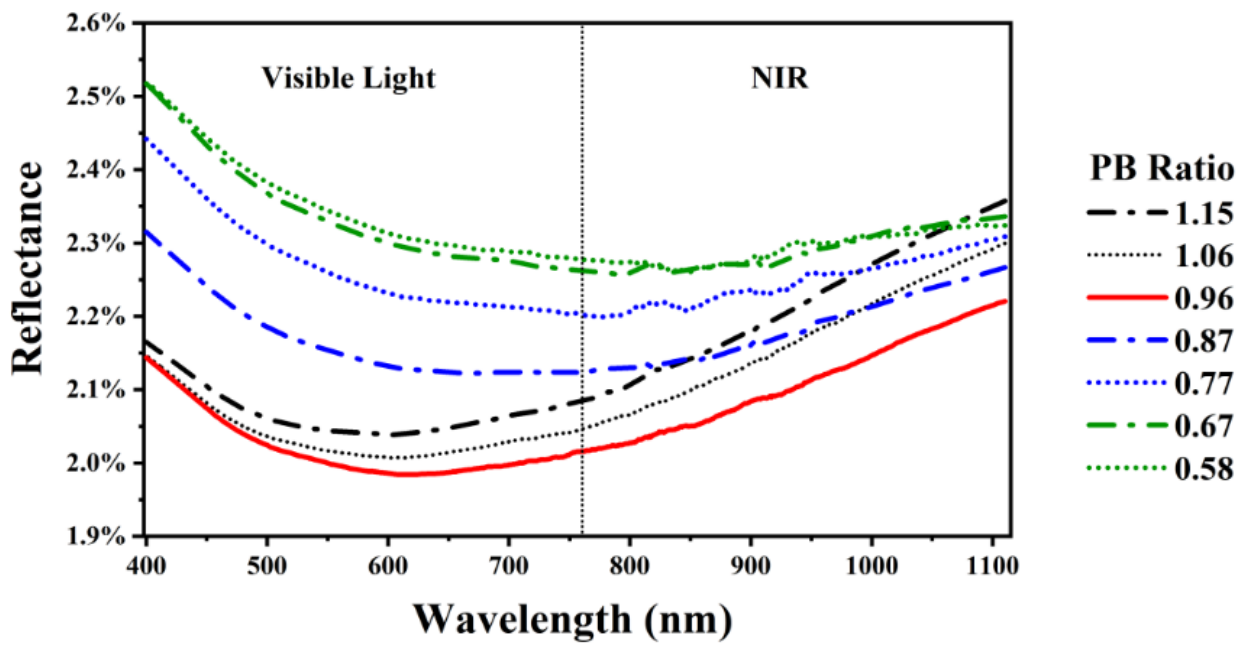

Figure 8. Reflectance of different PB ratio samples.

Table 1. Adhesion classification of different PB ratios according to ASTM and ISO standard methods.

\begin{tabular}{ccccc}
\hline \multirow{2}{*}{ PB Ratio } & \multicolumn{2}{c}{ Coatings as Prepared } & \multicolumn{2}{c}{ After Thermal Cycling Test } \\
ASTM D3359 & ISO 2409 & ASTM D3359 \\
\hline 1.15 & Class 1 & Class 4B & Class 2 & Class 3B \\
1.06 & Class 1 & Class 4B & Class 1 & Class 4B \\
0.96 & Class 0 & Class 5B & Class 0 & Class 5B \\
0.87 & Class 0 & Class 5B & Class 0 & Class 5B \\
0.77 & Class 0 & Class 5B & Class 0 & Class 5B \\
0.67 & Class 0 & Class 5B & Class 0 & Class 5B \\
0.58 & Class 0 & Class 5B & Class 0 & Class 5B \\
\hline
\end{tabular}

Ultra-black coating with high light absorption can be used not only for optical devices but also in aerospace applications such as satellites. For aerospace applications, coatings will be exposed to vacuum and starkly bear the extreme environment, where the temperature may be more than $150{ }^{\circ} \mathrm{C}$ for long periods. When the satellites travel around the earth, the surface temperature will rise significantly where the equipment is 
directly exposed to sunlight and will drop significantly when traveling through shadow areas [49]. Thus, the thermal cycling test was performed to simulate the space environment. The European Space Agency standard (ESA ECSS-Q-70-04A, 2008) and National Military standard of PRC (GJB 2052.8-2006) recommend a test where 100 heating-cooling $\left(100{ }^{\circ} \mathrm{C}\right.$ for heating and $-100{ }^{\circ} \mathrm{C}$ for cooling) cycles are performed with a dwell time of $5 \mathrm{~min}$. We performed the test strictly according to this standard. The samples were first placed in an oven at $100{ }^{\circ} \mathrm{C}$ for $10 \mathrm{~min}$ and then transferred into a freezing pump at $-100{ }^{\circ} \mathrm{C}$ within $10 \mathrm{~s}$ for another $5 \mathrm{~min}$. This cycling was repeated 100 times. After the thermal cycling test, the surface states were examined using the naked eyes for flaking and using an optical microscope for morphological damage. As we expected, there was hardly any change in the morphology compared with initial samples, indicating good stability of coatings in extreme environments. Light absorption property $(\% \mathrm{R})$ and adhesion grade were also tested. The reflectance remained the same, while the adhesion slightly decreased in high PB ratios samples. The samples having $\mathrm{PB}$ ratios above 0.96 show the worse adhesion test results, while the others exhibit the class 0/ ASTM class 5B adhesion (Table 1, Figure 9). The good adhesions in extreme cold and hot condition may be due to the moderate intramolecular flexibility of the polyurethane bond [50].
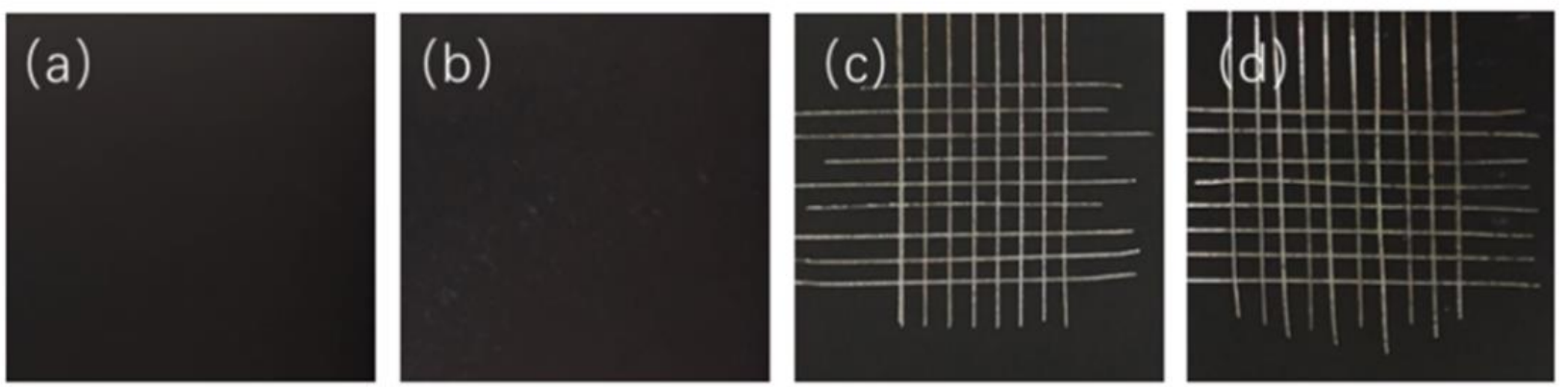

Figure 9. Typical adhesion test image of thermal cycling test of PB 0.96 samples. (a,c) Morphology and cross-cuts image before thermal cycling test. (b,d) Morphology and cross-cuts image after thermal cycling test.

\section{Conclusions}

In summary, in this study, we succeeded in preparing waterborne coatings composed of home-made activated CAs, which possess good adhesion and high optical absorption. In addition, the formulations for the preparation are commercially available and the process is reliable for large-scale production. The CAs were derived from resorcinol-formaldehyde resin (RFR) via sol-gel using a hydrothermal method, annealed, and reactivated using $\mathrm{CO}_{2}$. The ultra-black coatings of CAs comprising two-component waterborne polyurethane containing waterborne additives can be applied using different wet deposition methods, for example, spray coating, painting, and coil coating, which allow them to flatten and form a uniform film.

The adhesion properties and optical properties can be modified by adjusting the $\mathrm{CAs} /$ binder ratio, and we found the optimal ratio between absorption and adhesion to be 0.96 . For the sample with the adhesion grade as class 0 after the thermal cycling test, an average reflectance of $2.1 \%$ within the visible and NIR regions was achieved.

Author Contributions: G.G. conceived and designed the experiments; J.X. and Y.S. performed the experiments and wrote the paper; G.C. and J.L. review. All authors have read and agreed to the published version of the manuscript.

Funding: This research was supported by the National Key Research and Development Program of China (No.2017YFA0204600).

Institutional Review Board Statement: Not applicable.

Informed Consent Statement: Not applicable. 
Data Availability Statement: The data presented in this study are available in this article.

Acknowledgments: The assistance of laboratory members is greatly appreciated.

Conflicts of Interest: The authors declare no conflict of interest.

\section{References}

1. Korb, A.R.; Salisbury, J.W.; D'Aria, D.M. Thermal-infrared remote sensing and Kirchhoff's law: 2. Field measurements. J. Geophys. Res. Solid Earth 1999, 104, 15339-15350. [CrossRef]

2. Revzen, M.; Opher, R.; Opher, M.; Mann, A. Kirchhoff's theorem and the casimir effect. Europhys. Lett. 1997, 38, 245-248. [CrossRef]

3. Watts, C.M.; Liu, X.; Padilla, W.J. Metamaterial electromagnetic wave absorbers. Adv. Mater. 2012, 24, OP98-OP120. [CrossRef] [PubMed]

4. Jones, A.C.; O'Callahan, B.T.; Yang, H.U.; Raschke, M.B. The thermal near-field: Coherence, spectroscopy, heat-transfer, and optical forces. Prog. Surf. Sci. 2013, 88, 349-392. [CrossRef]

5. Song, J.; Hao, X.P.; Yuan, Z.D.; Liu, Z.L.; Ding, L. Research of ultra-black coating emissivity based on a controlling the surrounding radiation method. Int. J. Thermophys. 2018, 39. [CrossRef]

6. Salimian, S.; Zadhoush, A.; Naeimirad, M.; Kotek, R.; Ramakrishna, S. A review on aerogel 3D nanoporous structured fillers in polymer-based nanocomposites. Polym. Compos. 2017, 39, 3383-3408. [CrossRef]

7. Jackson, J.J.; Puretzky, A.A.; More, K.L.; Rouleau, C.M.; Geohegan, D.B. Pulsed growth of vertically aligned nanotube arrays with variable density. ACS Nano 2010, 4, 7573-7581. [CrossRef]

8. Zhai, M.; Liu, Y.; Huang, J.; Wang, Y.; Chen, K.; Fu, Y.; Li, H. Efficient suspension plasma spray fabrication of black titanium dioxide coatings with visible light absorption performances. Ceram. Int. 2019, 45, 930-935. [CrossRef]

9. Xing, F.; Zhao, B.; Shi, W. Study on tunable fabrication of the ultra-black Ni-P film and its blacking mechanism. Electrochim. Acta. 2012, 100, 157-163. [CrossRef]

10. Hadobás, K.; Kirsch, S.; Carl, A.; Acet, M.; Wassermann, E.F. Reflection properties of nanostructure-arrayed silicon surfaces. Nanotechnology 2000, 11, 161-164. [CrossRef]

11. Steglich, M.; Lehr, D.; Ratzsch, S.; Käsebier, T.; Schrempel, F.; Kley, E.-B.; Tünnermann, A. An ultra-black silicon absorber. Laser Photonics Rev. 2014, 8, L13-L17. [CrossRef]

12. Wang, Y.F.; Fu, W.G.; Feng, M.; Cao, X.W. Investigation of the structure and the physical properties of nickel-phosphorus ultra-black surfaces. Appl. Phys. A 2007, 90, 549-553. [CrossRef]

13. Panagiotopoulos, N.T.; Diamanti, E.K.; Koutsokeras, L.E.; Baikousi, M.; Kordatos, E.; Matikas, T.E. Nanocomposite catalysts producing durable, super-black carbon nanotube systems: Applications in solar thermal harvesting. ACS Nano 2012, 6, 1047510485. [CrossRef]

14. Zha, Z.; Yue, X.; Ren, Q.; Dai, Z. Uniform polypyrrole nanoparticles with high photothermal conversion efficiency for photothermal ablation of cancer cells. Adv. Mater. 2013, 25, 777-782. [CrossRef]

15. Jain, P.K.; Huang, X.; El-Sayed, I.H.; El-Sayed, M.A. Cheminform abstract: Noble metals on the nanoscale: Optical and photothermal properties and some applications in imaging, sensing, biology, and medicine. Acc. Chem. Res. 2007, 41, 1578-1586. [CrossRef]

16. Kaul, A.B.; Coles, J.B.; Eastwood, M.; Green, R.O.; Bandaru, P.R. Ultra-high optical absorption efficiency from the ultraviolet to the infrared using multi-walled carbon nanotube ensembles. Small 2013, 9, 1058-1065. [CrossRef]

17. De Rosa, I.M.; Sarasini, F.; Sarto, M.S.; Tamburrano, A. EMC impact of advanced carbon fiber/carbon nanotube reinforced composites for next-generation aerospace applications. IEEE Trans. Electromagn. Compat. 2008, 50, 556-563. [CrossRef]

18. Saxena, V.; Rani, R.U.; Sharma, A.K. Studies on ultra high solar absorber black electroless nickel coatings on aluminum alloys for space application. Surf. Coat. Technol. 2006, 201, 855-862. [CrossRef]

19. Arunnellaippan, T.; Rama Krishna, L.; Anoop, S.; Uma Rani, R.; Ramesbabu, N. Fabrication of multifunctional black PEO coatings on AA7075 for spacecraft applications. Surf. Coat. Technol. 2016, 307, 735-746.

20. Mousinho, A.P.; Mansano, R.D. Micropatterning of single-walled carbon nanotube forest. Prog. Org. Coat. 2011, 70, 326-329. [CrossRef]

21. Sun, Y.; Evans, J.; Ding, F.; Liu, N.; Liu, W.; Zhang, Y.; He, S. Bendable, ultra-black absorber based on a graphite nanocone nanowire composite structure. Opt. Express 2015, 23, 20115-20123. [CrossRef] [PubMed]

22. Wilson, S.J.; Hutley, M.C. The Optical Properties of 'Moth Eye' Antireflection Surfaces. Opt. Acta: Int. J. Opt. 2010, 29, 993-1009. [CrossRef]

23. Yu, K.; Fan, T.; Lou, S.; Zhang, D. Biomimetic optical materials: Integration of nature's design for manipulation of light. Prog. Mater. Sci. 2013, 58, 825-873. [CrossRef]

24. Zhao, Q.; Fan, T.; Ding, J.; Zhang, D.; Guo, Q.; Kamada, M. Super black and ultrathin amorphous carbon film inspired by anti-reflection architecture in butterfly wing. Carbon 2011, 49, 877-883. [CrossRef]

25. Yang, Z.P.; Hsieh, M.L.; Wilthan, B.; Bur, J.A.; Ajayan, P.M.; Ci, L.; Lin, S.Y.; Hanssen, L.M. Experimental observation of extremely weak optical scattering from an interlocking carbon nanotube array. Appl. Opt. 2011, 50, 1850-1855. [CrossRef] 
26. Azoubel, S.; Cohen, R.; Magdassi, S. Wet deposition of carbon nanotube black coatings for stray light reduction in optical systems. Surf. Coat. Technol. 2015, 262, 21-25. [CrossRef]

27. Sun, X.; Wei, Y.; Li, J.; Zhao, J.; Zhao, L.; Li, Q. Ultralight conducting PEDOT:PSS/carbon nanotube aerogels doped with silver for thermoelectric materials. Sci. China Mater. 2017, 60, 159-166. [CrossRef]

28. Wang, B.; Li, D.; Tang, M.; Ma, H.; Gui, Y.; Tian, X.; Quan, F.; Song, X.; Xia, Y. Alginate-based hierarchical porous carbon aerogel for high-performance supercapacitors. J. Alloys Compd. 2018, 749, 517-522. [CrossRef]

29. Zeng, F.Y.; Sui, Z.Y.; Liu, S.; Liang, H.P.; Zhan, H.H.; Han, B.H. Nitrogen-doped carbon aerogels with high surface area for supercapacitors and gas adsorption. Mater. Today Commun. 2018, 16, 1-7. [CrossRef]

30. Farhan, S.; Wang, R.; Jiang, H.; Li, K.; Wang, C. A novel combination of simple foaming and freeze-drying processes for making carbon foam containing multiwalled carbon nanotubes. Ceram. Int. 2016, 42, 8980-8989. [CrossRef]

31. Li, H.; Chen, Y.; Wang, P.; Xu, B.; Ma, Y.; Wen, W.; Yang, Y.; Fang, D. Porous carbon-bonded carbon fiber composites impregnated with $\mathrm{SiO}_{2}-\mathrm{Al}_{2} \mathrm{O}_{3}$ aerogel with enhanced thermal insulation and mechanical properties. Ceram. Int. 2018, 44, 3484-3487. [CrossRef]

32. Sun, X.; Li, Y. Colloidal carbon spheres and their core/shell structures with noble-metal nanoparticles. Angew. Chem. Int. Ed. Engl. 2004, 43, 597-601. [CrossRef]

33. Pilch-Pitera, B.; Czachor, D.; Kowalczyk, K.; Pavlova, E.; Wojturski, J.; Florczak, Ł.; Byczyński, Ł. Conductive polyurethane-based powder clear coatings modified with carbon nanotubes. Prog. Org. Coat. 2019, 137, 105367. [CrossRef]

34. Sun, W.; Du, A.; Gao, G.; Shen, J.; Wu, G. Graphene-templated carbon aerogels combining with ultra-high electrical conductivity and ultra-low thermal conductivity. Microporous Mesoporous Mater. 2017, 253, 71-79. [CrossRef]

35. Guo, J.; Li, D.; Zhao, H.; Zou, W.; Yang, Z.; Qian, Z.; Yang, S.; Yang, M.; Zhao, N.; Xu, J. Cast-and-use super black coating based on polymer-derived hierarchical porous carbon spheres. ACS Appl. Mater. Interfaces 2019, 11, 15945-15951. [CrossRef]

36. Xie, P.; Sun, W.; Liu, Y.; Du, A.; Zhang, Z.; Wu, G.; Fan, R. Carbon aerogels towards new candidates for double negative metamaterials of low density. Carbon 2018, 129, 598-606. [CrossRef]

37. Sun, W.; Du, A.; Feng, Y.; Shen, J.; Huang, S.; Tang, J.; Zhou, B. Super black material from low-density carbon aerogels with subwavelength structures. ACS Nano 2016, 10, 9123-9128. [CrossRef]

38. Yu, Z.L.; Wu, Z.Y.; Xin, S.; Qiao, C.; Yu, Z.Y.; Cong, H.P.; Yu, S.H. General and straightforward synthetic route to phenolic resin gels templated by chitosan networks. Chem. Mater. 2014, 26, 6915-6918. [CrossRef]

39. Li, F.; Xie, L.; Sun, G.; Kong, Q.; Su, F.; Cao, Y.; Wei, J.; Ahmad, A.; Guo, X.; Chen, C.M. Resorcinol-formaldehyde based carbon aerogel: Preparation, structure and applications in energy storage devices. Microporous Mesoporous Mater. 2019, 279 , $293-315$. [CrossRef]

40. Pekala, R.W.; Alviso, C.T.; Kong, F.M.; Hulsey, S.S. Aerogels derived from multifuctional organic monomers. J. Non Cryst. Solids 1991, 145, 90-98. [CrossRef]

41. Illera, D.; Mesa, J.; Gomez, H.; Maury, H. Cellulose aerogels for thermal insulation in buildings: Trends and challenges. Coatings 2018, 8, 345. [CrossRef]

42. ISO 2409, Paints and Varnishes-Cross-cut Test. 2013.

43. ASTM Stardard D 3359, Standard Test Methods for Measuring Adhesion by Tape Test, Method A; ASTM: Philadelphia, PA, USA, 2017.

44. Xu, Y.; Wang, S.; Yan, M.; Zhang, L.; Liu, Z. Synthesis, characterization and electrochemical properties of S-doped carbon aerogels. Solid State Ionics 2018, 321, 91-97. [CrossRef]

45. Xu, Y.; Ren, B.; Wang, S.; Zhang, L.; Liu, Z. Carbon aerogel-based supercapacitors modified by hummers oxidation method. J. Colloid Interface Sci. 2018, 527, 25-32. [CrossRef] [PubMed]

46. Li, X.; Liu, G.; Liu, S.; Ma, K.; Meng, L. The relationship between volatile fatty acids accumulation and microbial community succession triggered by excess sludge alkaline fermentation. J. Environ. Manag. 2018, 223, 85-91. [CrossRef]

47. Sing, K.S.W. Reporting physisorption data for gas/solid systems with special reference to the determination of surface area and porosity. Pure Appl. Chem. 1985, 57, 603-619. [CrossRef]

48. Xu, S.J.; Qiao, G.J.; Wang, H.J.; Li, D.C.; Lu, T.J. Preparation of mesoporous carbon derived from mixtures of phenol-formaldehyde resin and ethylene glycol. Mater. Lett. 2008, 62, 3716-3718. [CrossRef]

49. Bartosik, L.G.; Babel, H.W. Space environmental effects on spacecraft thermal control coatings. In Proceedings of the Space Simulation Conference: Confirming Spaceworthiness Into the Next Millennium, Albuquerque, NM, USA, 5-8 November 1990.

50. Li, M.; Qiang, X.; Xu, W.; Zhang, H. Synthesis, characterization and application of AFC-based waterborne polyurethane. Prog. Org. Coat. 2015, 84, 35-41. [CrossRef] 